\title{
Sweat Gland Duct
}

National Cancer Institute

\section{Source}

National Cancer Institute. Sweat Gland Duct. NCI Thesaurus. Code C33713.

The small tube that drains sweat from the sweat gland to the skin. 